\title{
Retraction method in fixed point theory for monotone nonexpansive mappings
}

\section{R. ALFURAidAN}

\section{ABSTRACT.}

In this paper we study the properties of the common fixed points set of a commuting family of monotone nonexpansive mappings in Banach spaces endowed with a graph. In particular, we prove that under certain conditions, this set is a monotone nonexpansive retract.

Acknowledgement. The author would like to acknowledge the support provided by the Deanship of Scientific Research at King Fahd University of Petroleum \& Minerals for funding this work through project No. IP142-MATH-111.

\section{REFERENCES}

[1] Alfuraidan, M. R., Fixed points of monotone nonexpansive mappings with a graph, Fixed Point Theory Appl., (2015), 2015:49, DOI 10.1186/s13663-015-0299-0

[2] Aronszajn, N. and Panitchpakdi, P., Extension of uniformly continuous transformations and hyperconvex metric spaces, Pacific J. Math., 6 (1956), 405-439

[3] Bachar, M. and Khamsi, M. A., Fixed points of monotone mappings and application to integral equations, Fixed Point Theory Appl., 2015, 2015:110, DOI:10.1186/s13663-015-0362-x

[4] Borsuk, K., Sur les rétractes, Fundam. Math., 17 (1931), 152-170

[5] Browder, F. E., Nonexpansive nonlinear operators in a Banach space, Proc. Nat. Acad. Sci. U.S.A., 54 (1965), 1041-1044

[6] Bruck, R. E., Properties of fixed point sets of non-expansive mappings in Banach spaces, Trans. Amer. Math. Soc., 179 (1973), 251-262

[7] Göhde, D., Zum Prinzip der kontraktiven Abbildung, Math. Nachr., 30 (1965), 251-258

[8] Granas, A. and Dugundji, J., Fixed point theory. Springer Monographs in Mathematics, Springer-Verlag, New York, 2003, xvi+690 pp. ISBN: 0-387-00173-5

[9] Jachymski, J., The Contraction Principle for Mappings on a Metric Space with a Graph, Proc. Amer. Math. Soc., 136 (2007), 1359-1373

[10] Johnsonbaugh, R., Discrete Mathematics, Prentice-Hall, Inc., New Jersey, 1997

[11] Kirk, W. A., A fixed point theorem for mappings which do not increase distances, Amer. Math. Monthly, 72 (1965), 1004-1006

[12] Klee, V. L., Stability of the fixed point property, Colloq. Math., 8 (1961), 43-46

[13] Ran, A. C. M. and Reurings, M. C. B., A fixed point theorem in partially ordered sets and some applications to matrix equations, Proc. Amer. Math. Soc., 132 (2004), 1435-1443

[14] Rival, I., A fixed point theorem for finite partially ordered sets, J. Combin. Theory, 21 (1976) 309-318

[15] Rival, I., The problem of fixed points in ordered sets, in: M. Deza and I. G. Rosenberg, eds., Annals of Discrete Mathematics, Vol. 8 (North-Holland, Amsterdam, 1980) 283-292

[16] Rus, I. A., The generalized retraction methods in fixed point theory for nonself operators, Fixed Point Theory, 15 (2014), No. 2, 559-578

Received: 01.02.2016; In revised form: 05.04.2016; Accepted: 30.04.2016

2010 Mathematics Subject Classification. 47H09, 46B20, 47H10, 47E10.

Key words and phrases. Common fixed point, monotone nonexpansive mapping, retract, Banach space, digraph, Strictly convex, Weakly Connected. 
[17] Rus, I. A. Retraction method in the fixed point theory in ordered structures, Seminar on Fixed Point Theory, 1-8, Preprint, 88-3, Univ. "Babes-Bolyai", Cluj-Napoca, 1988

[18] Tychonoff, A. N., ber die topologische Erweiterung von Rumen, Mathematische Annalen (in German) 102 (1930), No. 1, 544-561, doi:10.1007/BF01782364

DepartMENT OF MATHEMATiCS \& STATISTICS

King Fahd University of Petroleum and Minerals

DHAHRAN 31261, SAUDi ARABIA

E-mail address: monther@kfupm.edu.sa 